Article

\title{
Simple Analytical Strategy for Screening Three Synthetic Cathinones ( $\alpha$-PVT, $\alpha$-PVP, and MDPV) in Oral Fluids
}

\author{
André M. Segurado ${ }^{1}$, Samir M. Ahmad ${ }^{1,2,3, * \mathbb{D}}$, Nuno R. Neng ${ }^{1,4}\left(\mathbb{D}\right.$, Margarida M. Maniés-Sequeira ${ }^{5}$, \\ Helena Gaspar 4,5,6,*(D) and José Manuel F. Nogueira $1,4, * \mathbb{D}$
}

check for updates

Citation: Segurado, A.M.; Ahmad, S.M.; Neng, N.R.; Maniés-Sequeira, M.M.; Gaspar, H.; Nogueira, J.M.F. Simple Analytical Strategy for Screening Three Synthetic Cathinones ( $\alpha$-PVT, $\alpha$-PVP, and MDPV) in Oral Fluids. Analytica 2022, 3,14-23. https://doi.org/10.3390/ analytica3010002

Academic Editor: Marcello Locatelli

Received: 5 August 2021

Accepted: 15 December 2021

Published: 1 January 2022

Publisher's Note: MDPI stays neutral with regard to jurisdictional claims in published maps and institutional affiliations.

Copyright: (C) 2022 by the authors. Licensee MDPI, Basel, Switzerland. This article is an open access article distributed under the terms and conditions of the Creative Commons Attribution (CC BY) license (https:// creativecommons.org/licenses/by/ $4.0 /)$.
1 Centro de Química Estrutural, Institute of Molecular Sciences, Faculdade de Ciências, Universidade de Lisboa, Campo Grande, 1749-016 Lisboa, Portugal; segurado.csi@gmail.com (A.M.S.); ndneng@fc.ul.pt (N.R.N.)

2 Molecular Pathology and Forensic Biochemistry Laboratory, Centro de Investigação Interdisciplinar Egas Moniz (CiiEM), Instituto Universitário Egas Moniz (IUEM), Campus Universitário-Quinta da Granja, Monte da Caparica, 2829-511 Caparica, Portugal

3 Forensic and Psychological Sciences Laboratory Egas Moniz, Campus Universitário-Quinta da Granja, Monte da Caparica, 2829-511 Caparica, Portugal

4 Departamento de Química e Bioquímica, Faculdade de Ciências, Universidade de Lisboa, Campo Grande, 1749-016 Lisboa, Portugal

5 BioISI-Biosystems \& Integrative Sciences Institute, Faculdade de Ciências, Universidade de Lisboa, Campo Grande, 1749-016 Lisboa, Portugal; margarida.m.sequeira352@gmail.com

6 MARE-Marine and Environmental Sciences Centre, Polytechnic of Leiria, 2520-630 Peniche, Portugal

* Correspondence: smahmad@egasmoniz.edu.pt (S.M.A.); hmgaspar@fc.ul.pt (H.G.); nogueira@fc.ul.pt (J.M.F.N.)

\begin{abstract}
Synthetic cathinones are analogue compounds of the plant based stimulant cathinone. Its use, abuse, and related consumption complications have steadily increased in the last years. For this reason, there is a need for innovative analytical approaches that enable its rapid screening in biological matrices (e.g., oral fluids). The present work proposes a new analytical methodology by combining bar adsorptive microextraction followed by microliquid desorption and gas chromatography coupled to mass spectrometry (BA $\mu \mathrm{E}-\mu \mathrm{LD} / \mathrm{GC}-\mathrm{MS})$ for screening three synthetic cathinones $(\alpha-\mathrm{PVP}, \alpha-\mathrm{PVT}$, and MDPV) in oral fluids. The optimization of the BA $\mu$ E- $\mu$ LD/GC-MS methodology was successfully applied for the analysis of the target compounds in oral fluids. The results show average recoveries between 43.1 and $52.3 \%$ for the three synthetic cathinones. Good selectivity was also noticed. The developed methodology presents itself as an alternative tool to screen these compounds in oral fluids. To the best of our knowledge, this is the first work that combines a microextraction sorption-based technique followed by GC-MS analysis for the screening of synthetic cathinones in oral fluids.
\end{abstract}

Keywords: BA $\mu$ E; GC-MS; NMR; oral fluid; synthetic cathinones; MDPBP; MDPPP

\section{Introduction}

According to the United Nations Office on Drugs and Crime (UNDOC), new psychoactive substances (NPS) are "new narcotic or psychotropic drugs that are not listed in the Single Convention on Narcotic Drugs of 1961 or the Convention on Psychotropic Substances of 1971, but which may pose a public health threat comparable to that posed by substances listed in those conventions" [1]. These compounds have become an alternative to classic drugs, such as cocaine, ecstasy, heroin, or cannabis. By 2020, several hundreds of NPS have been detected and around 830 are now being monitored by the European Monitoring Centre for Drug and Drug Addition (EMCDDA). Synthetic cathinones (SC) are the second largest class of NPS being monitored by the EU Early Warning System (19\%), after synthetic cannabinoids (24\%) [2].

Cathinone is the main active compound present in the Catha edulis (Khat) plant. The use of this plant for its stimulant effects similar to amphetamine and methamphetamine goes back hundreds of years and is still extensively used by many people, mainly in 
East Africa and in the Arabic Peninsula [3]. Similarly, SC intends to mimic these effects. Since its first appearance in drug markets in the mid 2000s, many SCs have been identified, e.g., 4-methylmethcathinone (mephedrone), 3,4-methylenedioxypyrovalerone, naphyrone, 3,4-methylenedioxypyrovalerone (MDPV), $\alpha$-pyrrolidinopentiophenone ( $\alpha$-PVP), 3,4-Methylenedioxy- $\alpha$-pyrrolidinopropiophenone (MDPPP), methylone, butylone, 4-methylethcathinone, 4-fluoromethcathinone, $\alpha$-pyrrolidinopentiothiophenone $(\alpha-\mathrm{PVT})$, and $4^{\prime}$-methylenedioxy- $\alpha$-pyrrolidinobutiophenone (MDPBP), among many others [2]. Global seizures of SCs have steadily increased until it peaked in 2017. Nevertheless, the number of countries and quantities have increased, and SCs represented $8 \%$ of the global seizures of synthetic NPS (excluding ketamine) by weight in 2019 [1]. SCs are a particular toxic class of NPS, where several effects have been associated with its consumption, including nausea, hallucination, high blood pressure, and even death [4-7]. For these reasons, there is a need for innovative analytical methodologies that enable its screening in many types of biological matrices, especially via non-invasive approaches (e.g., oral fluids). Other advantages of using this biological matrix as an analysis medium are its fast sampling time, its difficulty to adulterate, its minimum or zero health hazards to the subject, and its representing of the free fraction of a drug [8,9]. Furthermore, it has already been shown that oral fluids can be used to monitor SCs since MDPV and $\alpha$-PVP have already been detected in the ranges of 20.5-831.7 and 81.9-935.0 $\mu \mathrm{g} \mathrm{L} \mathrm{L}^{-1}$, respectively [10].

Several analytical methodologies have been proposed for the determination of SCs in oral fluids, such as gas chromatography (GC) or high-performance liquid chromatography (HPLC) hyphenated to mass spectrometry systems (GC-MS and LC-MS or LC-MS/MS) [9-18]. These methodologies always include a previous enrichment step. Nowadays, the most popular miniaturized sorption-based extraction methods are solid-phase microextraction (SPME) and stir bar sorptive extraction (SBSE) [19]. However, other static microextraction techniques such as bar adsorptive microextraction $(\mathrm{BA} \mu \mathrm{E})$ have already proven to be suitable for the trace analysis of polar to non-polar analytes in aqueous media, including the analysis of legal and illegal drugs in several types of biological matrices [20-24]. It must be emphasized that although SCs suffer partial thermal degradation during GC-MS analysis $[25,26]$, it is pertinent to develop methodologies without derivatization since they provide more comprehensive and faster results.

The present contribution aimed to evaluate the performance of $\mathrm{BA} \mu \mathrm{E}$ followed by microliquid desorption $(\mu \mathrm{LD})$ prior to GC-MS operating in the selected ion-monitoring acquisition mode (SIM) to screen levels of six SCs, including $\alpha$-PVP, $\alpha$-PVT, MDPV, MDPBP, methylone, and MDPPP, in oral fluids. However, the last three were excluded in the optimized methodology due to partial thermal degradation. The optimization of the analytical procedure, including the influence of several experimental parameters, is fully discussed. To the best of our knowledge, this is the first work that reports the use of a miniaturized sorption-based technique in combination with the GC-MS system for the screening of the selected SCs in oral fluids.

\section{Materials and Methods}

\subsection{Standards and Materials}

The SCs standards of $\alpha-\mathrm{PVP}$ and MDPBP were previously synthetized with a purity of higher than 98\% [27,28], while methylone, MDPV, MDPPP, and $\alpha$-PVT were provided by the Forensic Sciences Laboratory from the Portuguese Judiciary Police (Lisbon, Portugal). Pure samples of methylone, MDPV, MDPPP, and $\alpha$-PVT were characterized through nuclear magnetic resonance (NMR). A small sample of each cathinone (10 to $15 \mathrm{mg}$ ) was dissolved in DMSO- $d_{6}$ in order to accomplish the NMR structural analysis (Bruker Advance spectrometer, Bremen, Germany) through ${ }^{1} \mathrm{H}$ NMR $(400.1 \mathrm{MHz})$ and ${ }^{13} \mathrm{C}$ NMR $(100.6 \mathrm{MHz})$. The chemical shifts were expressed as $\delta$ values and referenced to the residual solvent peak (DMSO- $d_{6}, \delta_{\mathrm{H}}=2.50$, and $\left.\delta_{\mathrm{C}}=39.5\right)$ using Hertz $(\mathrm{Hz})$ as the reporting unit for the coupling constants. One-dimensional $\left({ }^{1} \mathrm{H}\right.$ and $13 \mathrm{C}$ APT) and 2D (COSY, HMBC, and HSQC) NMR experiments were used to achieve the assignments of all ${ }^{1} \mathrm{H}$ and ${ }^{13} \mathrm{C}$ 
signals. The NMR data obtained for methylone and MDPV in DMSO were similar to previously reported data [29,30]. For MDPPP and $\alpha$-PVT, the NMR data were consistent with the literature data in different NMR solvents [31-33]. The full ${ }^{1} \mathrm{H}$ and ${ }^{13} \mathrm{C}$ NMR assignments for these last two SCs in DMSO are reported here for the first time. The purity of all the SCs ( $\geq 98 \%)$ was confirmed by GC-FID analysis using an Agilent GC system 7890B series with a flame ionization detector and Agilent 19091J-413 HP-5 capillary column (30 $\mathrm{m} \times 320 \mu \mathrm{m} \times 0.25 \mu \mathrm{m})$. Samples were dissolved in methanol/chloroform $(1 / 1, v / v)$ and $1 \mu \mathrm{L}$ of the solution was injected in split mode 40:1. The GC oven was programmed at $80{ }^{\circ} \mathrm{C}(1 \mathrm{~min})$ and heated at a rate of $12{ }^{\circ} \mathrm{C} / \mathrm{min}$ to $270{ }^{\circ} \mathrm{C}(7 \mathrm{~min})$. The NMR data can be found in the Supplementary Materials.

The employed solvents and materials were similar to previously published works [21,23], including HPLC-grade methanol (MeOH) and acetonitrile (ACN), as well as $\mathrm{NaCl}, \mathrm{NaOH}$, and $\mathrm{HCl}$ supplied by Carlo Erba (Arese, Italy), AnalaR BDH Chemicals (Lutterworth, UK), Riedel-de Haën (Seelze, Germany), Scharlau (Barcelona, Spain), and Panreac (Barcelona, Spain). The ultra-pure water was from Milli-Q water purification systems from Merck Millipore (Jaffrey, NH, USA). The commercial-activated carbon materials were SX1, N2, and R, supplied by Norit (Amersfoort, Netherlands) and supplied by both Salmon \& Cia. (Lisbon, Portugal) and Riedel-de Haën (Seelze, Germany). The polymeric phases tested were based on $N$-vinylpyrrolidone (Strata-X), styrene-divinylbenzene (PS-DVB) (StrataDVB), divinylbenzene (DVB), and pyrrolidone copolymer of weak cationic exchange (WCX) and ethylvinylbenzene polymer (LiChrolut EN), and were supplied by Phenomenex (Torrance, CA, USA) and Sigma-Aldrich (St. Louis, MI, USA). All polymers presented a $\mathrm{pH}$ stability between 1 and 14. The characteristics of the activated carbons and polymeric phases, such as the point of zero charge $\left(\mathrm{pH}_{\mathrm{PZC}}\right)$ and surface area, as well as the particle and pore sizes, can already be consulted in the literature [21,23]. Stock solutions of individual analytes $\left(1000.0 \mathrm{mg} \mathrm{L}^{-1}\right)$ were prepared in $\mathrm{MeOH}$, stored at $-20^{\circ} \mathrm{C}$, and renewed every month. Working standard mixtures of $10.0 \mu \mathrm{g} \mathrm{L}^{-1}$ were prepared daily using a $\mathrm{MeOH} / \mathrm{ACN}(1 / 1, v / v)$ solution and used for sample spiking. For instrumental calibration, standard mixtures were prepared in $\mathrm{MeOH}$ by appropriate dilution from previous stock solutions.

\section{2. $B A \mu E-\mu L D$ Assays}

The $\mathrm{BA} \mu \mathrm{E}$ devices $(7.5 \mathrm{~mm}$ in length and $3 \mathrm{~mm}$ in diameter) were lab-made and cleaned according to previously published reports [21-23]. The optimization assays were performed on $25 \mathrm{~mL}$ sampling flasks using ultra-pure water at $\mathrm{pH} 5.5$ spiked with the target compounds $\left(4.0 \mu \mathrm{g} \mathrm{L}^{-1}\right)$, followed by the introduction of a BA $\mathrm{EE}$ device coated with Strata$\mathrm{X}$ polymer and a conventional Teflon stir bar. The microextraction was achieved through magnetic stirring using a multipoint agitation plate (Variomag, Stuttgart, Germany) at room temperature (16 h at $750 \mathrm{rpm})$. After the microextraction, the Ba $\mu \mathrm{E}$ device was removed from the sampling flask, quickly dried, and introduced in a glass vial with a microinsert with $100 \mu \mathrm{L}$ of $\mathrm{MeOH} / \mathrm{ACN}(1 / 1, v / v)$, followed by ultrasonic treatment (Branson 3510, Fully, Switzerland) at room temperature for $45 \mathrm{~min}$. Finally, the BA $\mu \mathrm{E}$ device was removed, the vial closed, and put on the auto-sampler for instrumental analysis.

\subsection{Oral Fluid Samples}

The blank oral fluid samples were obtained from 11 volunteers ( 5 females and 6 males) by passive drooling into cryovials [8]. It was requested that the volunteers did not eat, drink, or smoke for at least $10 \mathrm{~min}$ before sampling. Additionally, the volunteers guaranteed that they did not consume any drugs of abuse for at least $24 \mathrm{~h}$ prior to sampling. After collection, the vials were closed and stored at $-20^{\circ} \mathrm{C}$. Whenever possible, the samples were analyzed on the same day.

In order to assess the recovery yields, sensitivity, and selectivity of the methodology for the analysis of the three SCs in oral fluids, the samples were previously centrifuged ( $5 \mathrm{~min}$ at $4000 \mathrm{rpm}$; Hermle Z 300, Wehingen, Germany). Afterwards, $0.5 \mathrm{~mL}$ of the supernatant 
(duplicate) was transferred to a vial containing $24.5 \mathrm{~mL}$ of ultra-pure water. Subsequently, the microextraction, back-extraction, and GC-MS(SIM) analysis was performed using optimized conditions. The recovery yields and sensitivity were assessed by spiking the centrifuged oral fluid samples $(0.5 \mathrm{~mL})$ with $100 \mu \mathrm{L}$ of the working standard at the desired concentrations and by performing the methodology using optimized conditions. The recovery was assessed by comparing the signal of the target compounds in the extract with neat solutions at the same concentrations. The sensitivity of the methodology was checked through the limits of detection (LODs) and calculated with a signal-to-noise ratio $(\mathrm{S} / \mathrm{N})$ of $3 / 1$. The selectivity was assessed by applying the optimized methodology on non-spiked oral fluid samples and by checking the resulting total ion chromatogram operating in the SIM mode for any interfering compounds, especially at the retention times of each compound.

\subsection{Instrumental Set-Up}

GC-MS analysis was performed using a similar instrumental system and method as already reported [17,19], except, in this case, we used the splitless injection mode at $250{ }^{\circ} \mathrm{C}$. The injection volume and speed were set at $2 \mu \mathrm{L}$ and $100 \mu \mathrm{L} \mathrm{min}{ }^{-1}$, respectively. The oven temperature was programmed from $60^{\circ} \mathrm{C}$ to $180^{\circ} \mathrm{C}$ at $30^{\circ} \mathrm{C} \mathrm{min}-1$ and to $300{ }^{\circ} \mathrm{C}$ (held for

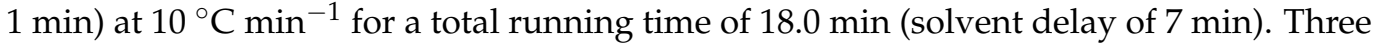
qualifier ions were chosen (Table 1), one of which was selected for quantification purposes, according to the characteristic features of the mass spectra obtained in the full-scan mode by comparison with the Wiley's library spectral data bank (G1035B; Rev D.02.00; Agilent Technologies, Waldbronn, Germany). The recovery data of all the performed assays were calculated through the comparison of the average peak areas of the extracted analytes with standard controls.

Table 1. Structures, $\log K_{\mathrm{O} / \mathrm{W}}, \mathrm{p} K_{\mathrm{a}}$, retention times $(\mathrm{RT})$, average recovery yields, and the precision (expressed in RSD) obtained for the three SCs by BA $\mu \mathrm{E}($ Strata- $\mathrm{X}$ )- $\mu \mathrm{LD} / \mathrm{GC}-\mathrm{MS}$ (SIM) in oral fluid samples under optimized experimental conditions.

\begin{tabular}{|c|c|c|c|c|c|c|}
\hline SCs & Chemical Structrure & $\begin{array}{l}\text { SIM ions } \\
\quad(m / z)\end{array}$ & $\begin{array}{c}\log \\
K_{\mathrm{O} / \mathrm{W}}{ }^{a}\end{array}$ & $\mathrm{p} K_{\mathrm{a}}{ }^{\mathrm{a}}$ & $\underset{\text { (min) }}{\mathrm{RT}}$ & $\begin{array}{c}\text { Recovery } \pm \\
\text { RSD } \\
(\%, n=5)\end{array}$ \\
\hline$\alpha$-PVP & & $77,105,126$ * & 3.36 & 7.49 & 8.9 & $43.1 \pm 13.2$ \\
\hline$\alpha$-PVT & & $84,111,126^{*}$ & 3.28 & 7.59 & 9.2 & $63.7 \pm 10.8$ \\
\hline MDPV & & $\begin{array}{c}121,126^{*} \\
149\end{array}$ & 2.99 & 7.31 & 12.2 & $52.3 \pm 13.2$ \\
\hline
\end{tabular}




\section{Results}

\subsection{Intrumental Operating Conditions}

In the present contribution, six SCs were selected for screening purposes in oral fluids. We started by evaluating the spectral fragmentation pattern of each SC using GC-MS(fullscan), which allowed us to choose the target (base peaks) and qualifier ions in order to achieve higher selectivity and sensitivity to operate in the SIM mode acquisition [15,25]. We chose $300^{\circ} \mathrm{C}$ as the injection temperature to start the instrumental optimization since it would ensure rapid volatilization of the target compounds. However, since methylone presented a very poor mass spectra quality, it was discarded from further studies. During the preliminary instrumental optimization, it was noticed that the other five SCs ( $\alpha$-PVP, $\alpha$-PVT, MDPPP, MDPBP, and MDPV) suffer partial thermal degradation during injection at $300{ }^{\circ} \mathrm{C}$, resulting in decomposition products characterized by prominent iminium base peaks with $m / z 2$ Da lower than the parent drug, as was already reported in previous works $[14,15]$. To minimize this phenomenon, the inlet temperature was programmed to $250{ }^{\circ} \mathrm{C}$, the initial hold time in the column was reduced from 1 to $0 \mathrm{~min}$, and the liner was changed every day (20 injections per day) in order to minimize or eliminate the possible occurrence of active sites during chromatographic analysis.

Under these conditions, the instrumental precision was evaluated through repeated injections $\left(2.0 \mathrm{mg} \mathrm{L}^{-1}, n=10\right)$, resulting in relative standard deviations (RSD) below $18.5 \%$ for $\alpha$-PVP, $\alpha$-PVT, and MDPV. Nevertheless, for MDPPP and MDPBP, the resulting signal was too unstable (RSD $>25 \%$ ) probably due to a more pronounced thermal degradation. For this reason, MDPPP and MDPBP were also discarded from further assays. By monitoring the selected ions of the remaining SCs (Table 1), good sensitivity and symmetrical peak shape could be obtained under the established conditions in suitable analytical time (<18.0 min). Figure S1 (Supplementary Materials) depicts the mass spectra for the three target SCs obtained using GC-MS analysis under the full-scan mode. Subsequently, instrumental sensitivity was checked through the limits of detection (LOD) and quantification (LOQ), obtained through the injection of diluted standard mixtures and calculated with a S/N of $3 / 1$ and 10/1, respectively. From the data obtained, values of $30.0 \mu \mathrm{g} \mathrm{L}^{-1}$ and $90.0 \mu \mathrm{g} \mathrm{L}^{-1}$ were achieved for all three SCs. Instrumental calibration was also performed using standard solutions with concentrations ranging from 250.0 to $20,000.0 \mu \mathrm{g} \mathrm{L}^{-1}$ (tenpoint calibration), in which some lack of linearity was observed $\left(r^{2}>0.92, \mathrm{MDPV}\right)$ due to partial thermal degradation. Even so, the instrumental calibration seemed suitable for qualitative analysis of the three SCs under study ( $\alpha$-PVP, $\alpha$-PVT, and MDPV).

\subsection{BA $\mu E-\mu L D$ Optimization Assays}

The proposed analytical approach, although user friendly and environmentally more favorable than conventional techniques, requires the optimization of several important parameters that can contribute to its effectiveness. To achieve this, the BA $\mu \mathrm{E}$ efficiency was evaluated using a univariate optimization strategy to optimize several parameters. We started by choosing the best sorbent coating (activated carbon or polymer) to microextract the target NPS from aqueous media. Afterwards, we optimized the desorption solvent $(\mathrm{ACN}, \mathrm{MeOH}$, and $\operatorname{mix}(\mathrm{MeOH} / \mathrm{ACN}, 1 / 1, v / v))$ and time $(15,30,45$, and $60 \mathrm{~min})$. Next, the magnetic stirring rate $(750,1000$, and $1250 \mathrm{rpm})$ and equilibrium time $(1,2,3$, and $16 \mathrm{~h})$ were also evaluated. Finally, sample $\mathrm{pH}(2.0,5.5$, and 12.0) as well as the addition of $\mathrm{NaCl}$ $(0,10$, and $20 \%, w / v)$ and $\mathrm{MeOH}(0,10$, and $20 \%, v / v)$ to the matrix were optimized. Except when specified, all assays were performed in triplicate.

Starting with the sorbent selection, three activated carbon materials (N2, SX1, and R) and four polymers (Strata-X, LiChrolut EN, Strata-DVB, and WCX) were tested as coating phases for enrichment purposes under standard conditions; microextraction stage: $16 \mathrm{~h}$ (1000 rpm), pH 5.5 (25 mL), and liquid desorption stage: $\mathrm{MeOH}(100 \mu \mathrm{L}), 30$ min under sonication treatment. By observing Figure $1 \mathrm{a}$, it was found that Strata-X (N-vinylpyrrolidonebased polymer) presented higher extraction efficiencies when compared to the other sorbents tested, resulting in average recoveries between $66.4 \%(\alpha-\mathrm{PVP})$ and $85.4 \%(\alpha-\mathrm{PVT})$. 

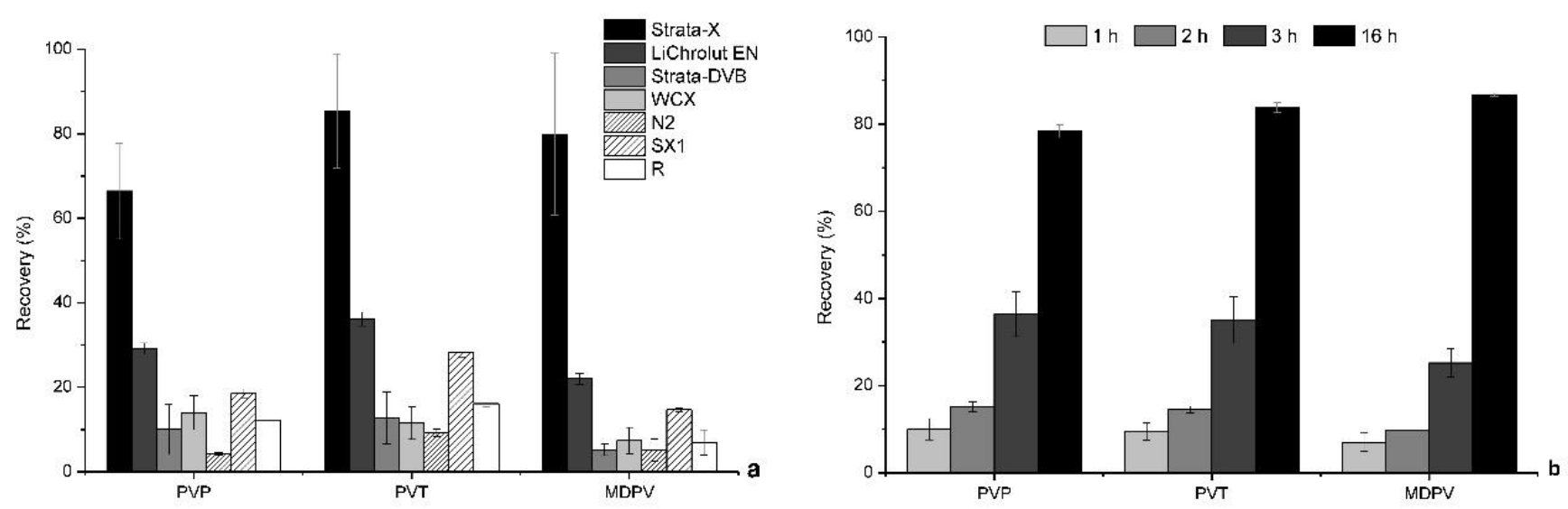

Figure 1. Effect of the sorbent selectivity (a) and equilibrium time (b) on the microextraction of the three SCs in aqueous media obtained by BA $\mu$ E- $\mu \mathrm{LD} / \mathrm{GC}-\mathrm{MS}(\mathrm{SIM})$. The experimental conditions (a) consisted of the microextraction stage of $16 \mathrm{~h}(1000 \mathrm{rpm}), \mathrm{pH} 5.5(25 \mathrm{~mL})$, and the liquid desorption stage: $\mathrm{MeOH}(100 \mu \mathrm{L}), 30 \mathrm{~min}$ under sonication treatment. The experimental conditions $(\mathbf{b})$ of microextraction with Strata-X-coated BA $\mu$ E devices at $750 \mathrm{rpm}$, pH $5.5(25 \mathrm{~mL})$, and liquid desorption stage: MIX $(100 \mu \mathrm{L})$ for $45 \mathrm{~min}$ under sonication. The error bars represent the standard deviation of three replicates.

After selecting the best sorbent coating (Strata-X) for BA $\mu \mathrm{E}$, we continued with the liquid desorption optimization process, which included the selection of the desorption solvent and sonication time. The results demonstrate (Figure S2, Supplementary Materials) that the solvent mixture using 45 min of sonication showed the best liquid desorption performance, with negligible advantages using longer periods of time.

Than, we decided to optimize the magnetic stirring rate and equilibrium time. The results (Figure S3, Supplementary Materials) proved that no significant differences are observed in the recovery yields. However, for higher stirring rates ( $\geq 1000 \mathrm{rpm})$, the Teflon stir bar can become unstable, creating higher turbulence, which may affect the BA $\mu \mathrm{E}$ device rotational motion, leading to poor precision. Therefore, $750 \mathrm{rpm}$ was selected for further assays. Furthermore, Figure $1 \mathrm{~b}$ shows that $16 \mathrm{~h}$ is needed to maximize the microextraction for all three SCs. Although this is a substantial period of time for microextraction, we decided to fix this parameter for further experiments since the BA $\mu \mathrm{E}$ technique can be performed overnight without any special requirements.

Finally, the effect of matrix $\mathrm{pH}$, ionic strength, and polarity were assayed in accordance with the experimental conditions described in Section 2.2. The results obtained demonstrate that the matrix $\mathrm{pH}$ greatly influences the recovery of the studied SCs (Figure S4, Supplementary Materials). Since a matrix $\mathrm{pH}$ of 5.5 resulted in higher extraction efficiency, this value was chosen for further studies. The results also demonstrate that the progressive addition of $\mathrm{MeOH}$ or $\mathrm{NaCl}$ (Figure S5, Supplementary Materials) significantly decreases the recovery yields of all three SCs. Therefore, the use of $\mathrm{NaCl}$ and $\mathrm{MeOH}$ were discarded.

From the data obtained, the experimental conditions optimized were as follows: microextraction stage: $16 \mathrm{~h}(750 \mathrm{rpm}), \mathrm{pH} 5.5$, and back-extraction stage: mix solvent $(100 \mu \mathrm{L}), 45 \mathrm{~min}$ under sonication.

\subsection{Application to Oral Fluid Samples}

After the optimization of the proposed methodology, the next step was to assess the applicability of the developed methodology for the analysis of $\alpha$-PVP, $\alpha$-PVT, and MDPV in real matrices. Therefore, several validation assays were performed using the optimized methodology on blank oral fluid samples (Section 2.3) in order to assess the recovery yields, sensitivity, and selectivity. The former was checked by a series of replicates $(n=5)$ in spiked oral fluid samples $\left(500.0 \mu \mathrm{g} \mathrm{L}{ }^{-1}\right)$, resulting in average recoveries $( \pm \mathrm{RSD}, \%)$ of $43.1( \pm 13.2 \%), 63.7( \pm 10.8 \%)$, and $52.3( \pm 13.6 \%)$ for $\alpha$-PVP, $\alpha$-PVT, and MDPV, respectively. 
The sensitivity of the methodology was also checked through the determination of the LODs by measuring the $\mathrm{S} / \mathrm{N}$ ratio of $3 / 1$ for all the target analytes. The data show that LODs of $100.0 \mu \mathrm{g} \mathrm{L}^{-1}$ were achieved for all three SCs under study, which shows that some matrix effects are noticed. To assess the selectivity, ten oral fluid samples were analyzed using the optimized methodology without spiking. The results show that no detectable compounds $(<\mathrm{LOD})$ eluted at the same RT of $\alpha$-PVP, $\alpha$-PVT, and MDPV (Figure 2 ). Despite all these data, the thermal degradation still continued to occur, probably due to oral fluid interferents, although all care to minimize this phenomenon were taken into consideration. For this reason, we decided that the GC-MS(SIM) approach was not suitable for the quantitative analysis of the three SCs. Despite this drawback, the optimized methodology could still be used as an alternative methodology to screen these three NPS in oral fluids. For this purpose, several assays were performed in duplicates by spiking five oral samples, to a final concentration of $500.0 \mu \mathrm{g} \mathrm{L}^{-1}$, under optimized experimental conditions. Figure 2 exemplifies the total ion chromatograms from spiked $\left(500.0 \mu \mathrm{g} \mathrm{L}^{-1}\right)$ and unspiked oral fluid samples, where good selectivity was noticed.

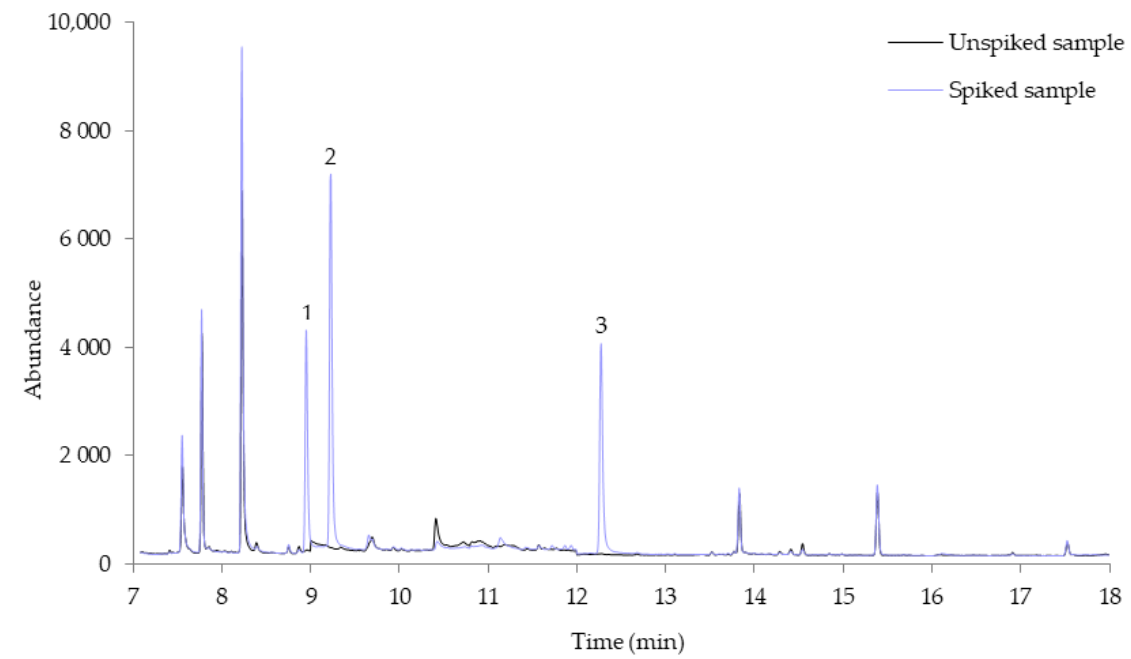

Figure 2. Total ion chromatograms from assays performed on spiked $\left(500.0 \mu \mathrm{g} \mathrm{L}^{-1}\right)$ and unspiked oral fluid samples obtained by BA $\mu \mathrm{E}($ Strata-X)- $\mu \mathrm{LD} / \mathrm{GC}-\mathrm{MS}(\mathrm{SIM})$ under optimized experimental conditions. 1: $\alpha$-PVP; 2: $\alpha$-PVT; and 3: MDPV.

As was stated before, although the developed methodology cannot be accurately used for quantitative purposes, it can still be used to detect and confirm the presence of the three SCs in oral fluids since these compounds have previously been detected in this type of sample matrix in the ranges proposed by this approach. For instance, other researchers have detected MDPV and $\alpha$-PVP in the range of 20.5-831.7 and 81.9-935.0 $\mu \mathrm{g} \mathrm{L} \mathrm{L}^{-1}$, respectively [10]. It must also be emphasized that the application of an analytical methodology using the GC-MS system without derivatization, even under all these limitations, can be a simple alternative for screening types of compounds in oral fluids.

\section{Discussion}

SCs are the second most seized NPS in Europe and one of the most abused drugs around the word after the "classic" ones. For this reason, novel miniaturized and green analytical methodologies are needed to screen these compounds in several biological matrices. In this regard, oral fluid can be an excellent source to monitor SC short-term consumption while being fast and easy to collect [8]. This is particularly important to police driving under the influence of drugs. While the sample can be analyzed on site using fast detection kits, this cannot be easily performed for recently introduced NPS on the market since they have distinct physico-chemical characteristics from classical drugs. For this reason, presumptive positive samples must be later confirmed using more 
advanced techniques such as LC-MS and GC-MS. While the former is a more frequently used instrumental system to analyze SCs in biological matrices, the latter is much cheaper, more comprehensive, and is ubiquitous in most analytical toxicology laboratories. Our results show that although the target SCs present partial thermal degradation during GCMS(SIM) analysis, this phenomenon can be minimized by lowering injection temperatures and residence time at the inlet, and by avoiding active sites during chromatographic analysis (i.e., replacing liners more often) as previously suggested [25]. This data show that although reliable quantitation is limited using GC-MS(SIM), a suitable qualitative approach can be employed, especially taking into consideration the demand for alternative analytical methodologies for the trace detection of these compounds and the public health issues regarding its abuse. The validation assays showed that the reproducibility using pentaplicates is acceptable for this type of application $(\mathrm{RSD}<15 \%)$ for samples presenting levels of the target compounds higher than $100 \mu \mathrm{g} \mathrm{L}^{-1}$.

The optimized sample preparation stage, using an $\mathrm{N}$-vinylpyrrolidone sorbent phase as coating material for $\mathrm{BA} \mu \mathrm{E}$, showed very good performance for the detection of traces of $\alpha$-PVP, $\alpha$-PVT, and MDPV in oral fluid samples. This sorbent material combines small particle $(33 \mu \mathrm{m})$ and pores sizes $(85 \AA)$, high surface area $\left(800 \mathrm{~m}^{2} \mathrm{~g}^{-1}\right)$, and the possibility to retain analytes by reverse-phase type interactions, i.e., hydrogen bonding, $\pi-\pi$, and dipole-dipole and hydrophobic interactions, especially for compounds with mid-polar to non-polar characteristics such as the target SCs under study $\left(\log K_{\mathrm{O} / \mathrm{W}} \approx 3\right.$; Table 1$)$. In this particular case, the resulting efficiency may be attributed to dipole-dipole interactions between the pyrrolidone of the polymer and the electronegative groups in the target SCs. Furthermore, $\pi-\pi$ and hydrophobic interactions promoted by the DVB groups may also contribute to the high retention of $\alpha$-PVP, $\alpha$-PVT, and MDPV. The $\mu$ LD process showed that a mixture of the two solvents produced the best results, which is expected when analyzing compounds with different chemical structures. Although the optimized conditions showed that $16 \mathrm{~h}$ are needed to reach the microextraction equilibrium, it is not really a limitation using $\mathrm{BA} \mu \mathrm{E}$ since it can be performed overnight with no special requirements. In regard to sample $\mathrm{pH}$, since the target $\mathrm{SC}$ s presented weak base characteristics with $\mathrm{p} K_{\mathrm{a}}$ values between 7.31 and 7.89 [34], it was expected that lower $\mathrm{pH}$ values would provide a loss in efficiency and a more basic solution the opposite. However, the best results were obtained at almost neutral $\mathrm{pH}$, suggesting that an equilibrium between neutral and ionized forms of the compounds are favored to the microextraction process. This may be attributed to the lipophilic-hydrophilic nature of Strata-X. Finally, since the target SCs presented mostly non-polar characteristics, with $\log p$ values between 2.99 and 3.36, it was expected that the addition of salt or an organic modifier would not increase the overall efficiency [22].

It must be emphasized that the back-extraction stage and the overall analytical process uses only $100 \mu \mathrm{L}$ of organic solvent per sample $(\mathrm{MeOH} / \mathrm{ACN}, 1 / 1, v / v)$. This represents a 16 or 15-fold decrease when compared to analytical methodologies that employed dispersive liquid-liquid microextraction [13] or solid-phase extraction [17], respectively, without significant loss in efficiency. Additionally, the proposed methodology is absent of memory effects since $\mathrm{BA} \mu \mathrm{E}$ devices are designed to be used only once because they are very cheap, as well as easy and simple to prepare in a lab. This is a great advantage over other microextraction devices such as microextraction by packed sorbent [11], which has a limited number of applications before exhibiting a decrease in efficiency. Furthermore, these devices always need additional cleaning and washing steps after being used.

To the best of our knowledge, this is the first work that combines a microextraction sorption-based technique followed by GC-MS analysis for screening traces of $\alpha$-PVP, $\alpha$-PVT, and MDPV in oral fluid samples. 
Supplementary Materials: The following supporting information can be downloaded at: https: / / www.mdpi.com/article/10.3390/analytica3010002/s1, Figure S1: Mass spectra of $\alpha$-PVP, $\alpha$-PVT and MDPV obtained by GC-MS under full-scan mode; Figure S2: Effect of the back-extraction solvent (a) time (b) on the microextraction of the three SCs in aqueous media, obtained by BA $\mu \mathrm{E}-\mu \mathrm{LD} / \mathrm{GC}$ MS(SIM). The error bars represent the standard deviation of three replicates; Figure S3: Effect of stirring rate on the microextraction of the three SCs in aqueous media, obtained by BA $\mu \mathrm{E}-\mu \mathrm{LD} / \mathrm{GC}$ MS(SIM). The error bars represent the standard deviation of three replicates; Figure S4: Effect matrix $\mathrm{pH}$ on the microextraction of the three SCs in aqueous media, obtained by BA $\mu$ E- $\mu \mathrm{LD} / \mathrm{GC}-\mathrm{MS}(\mathrm{SIM})$. The error bars represent the standard deviation of three replicates; Figure S5: Effect of matrix MeOH (a) and $\mathrm{NaCl}$ (b) content on the microextraction of the three SCs in aqueous media, obtained by $\mathrm{BA} \mu \mathrm{E}-\mu \mathrm{LD} / \mathrm{GC}-\mathrm{MS}(\mathrm{SIM})$. The error bars represent the standard deviation of three replicates.

Author Contributions: Conceptualization, S.M.A. and H.G.; methodology, A.M.S. and M.M.M.-S.; validation, S.M.A., N.R.N. and H.G.; formal analysis, A.M.S., S.M.A. and H.G.; investigation, A.M.S. and M.M.M.-S.; writing-original draft preparation, A.M.S. and S.M.A.; writing-review and editing, N.R.N., H.G. and J.M.F.N.; supervision, N.R.N., H.G. and J.M.F.N.; funding acquisition, H.G. and J.M.F.N. All authors have read and agreed to the published version of the manuscript.

Funding: The authors thank Fundação para a Ciência e a Tecnologia (Portugal) for financial support for the projects UIDB/00100/2020 and UIDP/00100/2020 granted to CQE (Centro de Química Estrutural), UID/04292/2020 granted to MARE (Marine and Environmental Sciences Centre), UIDP/04046/2020 and UIDB/04046/2020 granted to BioISI (BioSystems and Integrative Sciences Institute), and the Ph.D. grant (SFRH/BD/107892/2015) and for the contract established from DL 57/2016.

Data Availability Statement: All relevant data are within the manuscript.

Acknowledgments: The authors thank "Laboratório de Polícia Científica da Polícia Judiciária" for providing the synthetic cathinones within the protocol established with the "Faculdade de Ciências da Universidade de Lisboa".

Conflicts of Interest: The authors declare no conflict of interest.

\section{References}

1. World Drug Report 2021 (United Nations publication, Sales No. E.21.XI.8). Available online: https://www.unodc.org/unodc/ en/data-and-analysis/wdr2021.html (accessed on 23 July 2021).

2. European Monitoring Centre for Drugs and Drug Addiction. European Drug Report 2021: Trends and Developments; Publications Office of the European Union: Luxembourg, 2021.

3. El-Menyar, A.; Mekkodathil, A.; Al-Thani, H.; Al-Motarreb, A. Khat use: History and heart failure. Oman Med. J. 2015,30 , 77-82. [CrossRef]

4. Capriola, M. Synthetic cathinone abuse. Clin. Pharmacol. Adv. Appl. 2013, 5, 109-115. [CrossRef]

5. Imam, S.F.; Patel, H.; Mahmoud, M.; Prakash, N.A.; King, M.S.; Fremont, R.D. Bath salts intoxication: A case series. J. Emerg. Med. 2013, 45, 361-365. [CrossRef] [PubMed]

6. Zaami, S.; Giorgetti, R.; Pichini, S.; Pantano, F.; Marinelli, E.; Busardò, F.P. Synthetic cathinones related fatalities: An update. Eur. Rev. Med. Pharmacol. Sci. 2018, 22, 268-274. [CrossRef]

7. La Maida, N.; Di Trana, A.; Giorgetti, R.; Tagliabracci, A.; Busardò, F.P.; Huestis, M.A. A Review of Synthetic Cathinone-Related Fatalities From 2017 to 2020. Ther. Drug Monit. 2021, 43, 52-68. [CrossRef]

8. Elmongy, H.; Abdel-Rehim, M. Saliva as an alternative specimen to plasma for drug bioanalysis. A review. TrAC-Trends Anal. Chem. 2016, 83, 70-79. [CrossRef]

9. Graziano, S.; Anzillotti, L.; Mannocchi, G.; Pichini, S.; Busardò, F.P. Screening methods for rapid determination of new psychoactive substances (NPS) in conventional and non-conventional biological matrices. J. Pharm. Biomed. Anal. 2019, 163, 170-179. [CrossRef] [PubMed]

10. Amaratunga, P.; Lemberg, B.L.; Lemberg, D. Quantitative measurement of synthetic cathinones in oral fluid. J. Anal. Toxicol. 2013, 37, 622-628. [CrossRef]

11. Ares, A.M.; Fernández, P.; Regenjo, M.; Fernández, A.M.; Carro, A.M.; Lorenzo, R.A. A fast bioanalytical method based on microextraction by packed sorbent and UPLC-MS/MS for determining new psychoactive substances in oral fluid. Talanta 2017, 174, 454-461. [CrossRef]

12. de Castro, A.; Lendoiro, E.; Fernández-Vega, H.; Steinmeyer, S.; López-Rivadulla, M.; Cruz, A. Liquid chromatography tandem mass spectrometry determination of selected synthetic cathinones and two piperazines in oral fluid. Cross reactivity study with an on-site immunoassay device. J. Chromatogr. A 2014, 1374, 93-101. [CrossRef] 
13. Fernández, P.; Regenjo, M.; Ares, A.; Fernández, A.M.; Lorenzo, R.A.; Carro, A.M. Simultaneous determination of 20 drugs of abuse in oral fluid using ultrasound-assisted dispersive liquid-liquid microextraction. Anal. Bioanal. Chem. 2019, 411, 193-203. [CrossRef]

14. Mohamed, K.M.; Al-Hazmi, A.H.; Alasiri, A.M.; Ali, M.E.-S. A GC-MS Method for Detection and Quantification of Cathine, Cathinone, Methcathinone and Ephedrine in Oral Fluid. J. Chromatogr. Sci. 2016, 54, 1271-1276. [CrossRef]

15. Strano-Rossi, S.; Cadwallader, A.B.; de la Torre, X.; Botrè, F. Toxicological determination and in vitro metabolism of the designer drug methylenedioxypyrovalerone (MPDV) by gas chromatography/mass spectrometry and liquid chromatography/quadrupole time-of-flight mass spectrometry. Rapid Commun. Mass Spectrom. 2010, 24, 2706-2714. [CrossRef]

16. Strano-Rossi, S.; Anzillotti, L.; Castrignanò, E.; Romolo, F.S.; Chiarotti, M. Ultra high performance liquid chromatographyelectrospray ionization-tandem mass spectrometry screening method for direct analysis of designer drugs, "spice" and stimulants in oral fluid. J. Chromatogr. A 2012, 1258, 37-42. [CrossRef] [PubMed]

17. Sorribes-Soriano, A.; Esteve-Turrillas, F.A.; Armenta, S.; Amorós, P.; Herrero-Martínez, J.M. Amphetamine-type stimulants analysis in oral fluid based on molecularly imprinting extraction. Anal. Chim. Acta 2019, 1052, 73-83. [CrossRef]

18. Di Trana, A.; Mannocchi, G.; Pirani, F.; La Maida, N.; Gottardi, M.; Pichini, S.; Busardò, F.P. A comprehensive HPLC-MS-MS screening method for 77 new psychoactive substances, 24 classic drugs and 18 related metabolites in blood, urine and oral fluid. J. Anal. Toxicol. 2020, 44, 769-783. [CrossRef] [PubMed]

19. Nogueira, J.M.F. Stir-bar sorptive extraction-15 years making sample preparation more environment friendly. TrAC Trends Anal. Chem. 2015, 71, 214-223. [CrossRef]

20. Neng, N.R.; Ahmad, S.M.; Gaspar, H.; Nogueira, J.M.F. Determination of mitragynine in urine matrices by bar adsorptive microextraction and HPLC analysis. Talanta 2015, 144, 105-109. [CrossRef]

21. Ahmad, S.M.; Nogueira, J.M.F. High throughput bar adsorptive microextraction: A simple and effective analytical approach for the determination of nicotine and cotinine in urine samples. J. Chromatogr. A 2019, 460750. [CrossRef] [PubMed]

22. Ahmad, S.M.; Nogueira, J.M.F. High throughput bar adsorptive microextraction: A novel cost-effective tool for monitoring benzodiazepines in large number of biological samples. Talanta 2019, 199, 195-202. [CrossRef]

23. Ahmad, S.M.; Oliveira, M.N.; Neng, N.R.; Nogueira, J.M.F. A fast and validated high throughput bar adsorptive microextraction $(\mathrm{HT}-\mathrm{BA} \mu \mathrm{E})$ method for the determination of ketamine and norketamine in urine samples. Molecules 2020, 25, 1438. [CrossRef] [PubMed]

24. Oliveira, M.N.; Gonçalves, O.C.; Ahmad, S.M.; Schneider, J.K.; Krause, L.C.; Neng, N.R.; Caramão, E.B.; Nogueira, J.M.F. Application of Bar Adsorptive Microextraction for the Determination of Levels of Tricyclic Antidepressants in Urine Samples. Molecules 2021, 26, 3101. [CrossRef] [PubMed]

25. Kerrigan, S.; Savage, M.; Cavazos, C.; Bella, P. Thermal degradation of synthetic cathinones: Implications for forensic toxicology. J. Anal. Toxicol. 2016, 40,1-11. [CrossRef]

26. DeRuiter, J.; Hayes, L.; Valaer, A.; Clark, C.R.; Noggle, F.T. Methcathinone and Designer Analogues: Synthesis, Stereochemical Analysis, and Analytical Properties. J. Chromatogr. Sci. 1994, 32, 552-564. [CrossRef]

27. Gaspar, H.; Bronze, S.; Oliveira, C.; Victor, B.L.; Machuqueiro, M.; Pacheco, R.; Caldeira, M.J.; Santos, S. Proactive response to tackle the threat of emerging drugs: Synthesis and toxicity evaluation of new cathinones. Forensic Sci. Int. 2018, 290, 146-156. [CrossRef] [PubMed]

28. Gaspar, H.; Bronze, S.; Ciríaco, S.; Queirós, C.R.; Matias, A.; Rodrigues, J.; Oliveira, C.; Cordeiro, C.; Santos, S. 4F-PBP (4'-fluoro$\alpha$-pyrrolidinobutyrophenone), a new substance of abuse: Structural characterization and purity NMR profiling. Forensic Sci. Int. 2015, 252, 168-176. [CrossRef]

29. Westphal, F.; Junge, T.; Rösner, P.; Sönnichsen, F.; Schuster, F. Mass and NMR spectroscopic characterization of 3,4methylenedioxypyrovalerone: A designer drug with $\alpha$-pyrrolidinophenone structure. Forensic Sci. Int. 2009, 190, 1-8. [CrossRef]

30. Maheux, C.R.; Copeland, C.R.; Pollard, M.M. Characterization of Three Methcathinone Analogs: 4-Methylmethcathinone, Methylone, and bk-MBDB. Microgram J. 2010, 7, 42-49.

31. Scientific Working Group for the Analysis of Seized Drugs (SWGDRUG), Drugs Monographs, MDPPP, 2013. Available online: http:/ / www.swgdrug.org/Monographs/MDPPP.pdf (accessed on 30 May 2021).

32. Uchiyama, N.; Matsuda, S.; Kawamura, M.; Kikura-Hanajiri, R.; Goda, Y. Two new-type cannabimimetic quinolinyl carboxylates, QUPIC and QUCHIC, two new cannabimimetic carboxamide derivatives, ADB-FUBINACA and ADBICA, and five synthetic cannabinoids detected with a thiophene derivative $\alpha$-PVT and an opioid receptor agonist AH-79. Forensic Toxicol. 2013, 31, 223-240. [CrossRef]

33. Doi, T.; Asada, A.; Takeda, A.; Tagami, T.; Katagi, M.; Matsuta, S.; Kamata, H.; Kawaguchi, M.; Satsuki, Y.; Sawabe, Y.; et al. Identification and characterization of $\alpha$-PVT, $\alpha$-PBT, and their bromothienyl analogs found in illicit drug products. Forensic Toxicol. 2016, 34, 76-93. [CrossRef]

34. Marvin 6 2.2, ChemAxon. Available online: http:/ / www.chemaxon.com (accessed on 23 July 2021). 